doi) https://doi.org/10.31977/grirfi.v20i2.1473

Recebido: 28/10/2019 | Aprovado: 26/04/2020

Received: 10/28/2019 | Approved: 04/26/2020

\title{
ESTADO PASTORAL E GOVERNO POLÍTICO DOS HOMENS
}

\author{
Cícero Josinaldo da Silva Oliveira ${ }^{1}$ \\ Universidade Federal de Goiás (UFG) \\ https://orcid.org/0000-0002-4517-8510 \\ E-mail: cicerojosinaldo@ufg.br
}

\section{RESUMO:}

Servindo-nos do referencial foucaultiano examinamos aqui o pressuposto básico do ordenamento político moderno e contemporâneo, a saber, a concepção decisiva de que os homens são governáveis. No percurso genealógico aberto por Michel Foucault examinamos a reelaboração política do que fora originalmente o poder espiritual judaico-cristão de governo das almas. Para Foucault, o moderno governo político dos homens está situado no cruzamento de dois conjuntos de poderes prefigurados no cristianismo primitivo: a) a arte pastoral de conduzir condutas; deslocada da destinação escatológica das almas à gestão calculada da vida biológica (biopolítica) e b) a dupla produção do conhecimento necessário ao bom governo; a produção utilitária da verdade que serve à própria arte pastoral de governo e a manifestação pura ou aletúrgica da verdade a propósito dos governáveis.

PALAVRAS-CHAVE: Poder pastoral; Governo; Condução; Verdade; Estado-moderno.

\section{PASTORAL STATE AND MEN'S POLITICAL GOVERNMENT}

\begin{abstract}
:
Using the Foucaultian framework, we examine here the basic assumption of the modern and contemporary political order, namely the decisive conception that men are governable. In the genealogical path opened by Michel Foucault we examined the political reworking of what was originally the Judeo-Christian spiritual power of governing souls. For Foucault, the modern political government of men is situated at the intersection of two sets of powers foreshadowed in early Christianity: a) the pastoral art of conducting conduct displaced from the eschatological destination of souls to the calculated management of (biopolitical) biological life and b) the dual production of the knowledge necessary for good governance; the utilitarian production of the truth that serves the pastoral art of government itself and the pure or aleturgical manifestation of the truth with regard to the governable.
\end{abstract}

KEYWORDS: Pastoral power; Government; Driving; Truth; Modern state.

\footnotetext{
1Doutor em Filosofia pela Pontifícia Universidade Católica do Rio de Janeiro (PUC-RIO), Rio de Janeiro - Brasil. Professor de Filosofia da Universidade Federal do Goiás (UFG), Cidade de Goiás - GO, Brasil.
}

OLIVEIRA, Cícero Josinaldo da Silva. Estado pastoral e governo político dos homens. Griot : Revista de Filosofia, Amargosa BA, v.20, n.2, p.75-87, junho, 2020. 


\section{A matriz pastoral das artes de governar}

No pensamento de Michel Foucault a expressão "governo político dos homens" não deve de modo algum soar redundante, como se governar fosse uma tarefa exclusiva ou mesmo originária do domínio político.

"Governar", como nos esclarece genealogicamente o autor, implica o exercício de guiar, o poder de imprimir comportamentos, de conduzir condutas a partir de metas precisas e técnicas distintas, constitutivas de atribuições, saberes, tarefas, encargos, artes e ofícios polissêmicos, dentre os quais o governo político do soberano ou do Estado sobre os homens é na verdade dos mais tardios, a despeito de ser seguramente o mais complexo e aparelhado, estando ainda hoje em franco desenvolvimento.

Em contraste, a expressão "gestão governamental", bastante corrente no vocabulário político hodierno, deve ser lida como a competência própria da arte política de governo, da boa condução pública dos homens que tema economia-política como símbolo maior da rede de saber/poder articuladora do encargo público. Com efeito, "governar" no sentido político vigente de "administrar", de fazer a adequada "condução", a boa "gestão" dos homens e das coisas, implica o reconhecimento e o recorte da população como um nível específico da realidade humana, com saberes e formas características de intervenções confiadas ao governo que é aqui particularmente compreendido como um determinado saber-poder político e econômico.

Desde o século XVIII, quando começa a adquirir o sentido político que hoje conhecemos, o governo ou "a arte de governar é, precisamente, a arte de exercer o poder na forma e segundo o modelo da economia" (FOUCAULT, 2008b, p. 127). Neste ínterim, assim como a noção de um governo político, a expressão governo econômico tornou-se no fundo um pleonasmo, uma tautologia.

O diagnóstico foucaultiano de que a modernidade, já em seu limiar, é marcada pelo nascimento da biopolítica, implica a simbiose moderna entre política e economia sob a mediação da vida. Para Foucault, a vida humana enquanto fenômeno meramente biológico se vê engastada nas novas engrenagens do poder pela tecnologia disciplinar do trabalho; consagrada à utilidade-docilidade corpo, e depois simultaneamente administrada como fenômeno de massa cujos suportes naturais são as populações; alvos de uma gestão governamental cujo propósito é "melhorar a sorte das populações, aumentar suas riquezas, sua duração de vida, sua saúde" (FOUCAULT, 2008b, p. 149). Foucault insiste que o governo econômico nas formas históricas como até aqui o conhecemos (mercantilismo, liberalismo e neoliberalismo) é sempre um governo biopolítico.

No curso Do governo dos vivos (1980), lançando um olhar retrospectivo a propósito de suas primeiras genealogias em torno do conceito de "governo", em como de sua ressignificação política explorada nos cursos Segurança, território, população (1978) e Nascimento da biopolítica (1979), Foucault diz o seguinte:

\footnotetext{
Nos cursos dos dois últimos anos eu, portanto, tentei esboçar um pouco essa noção de governo que me pareceu ser muito mais operatória que a noção de poder; governo entendido seguramente não no sentido estreito e atual de instância suprema de decisões executivas e administrativas em um sistema estatal, mas no sentido largo e antigo de mecanismos e procedimentos destinados a conduzir os homens, a dirigir a conduta dos homens. E foi no quadro geral dessa noção de governo que eu tentei estudar duas coisas a título de exemplo: de um lado, o nascimento da razão de Estado no século XVII entendida não como teoria ou representação do Estado, mas como arte de governar, como racionalidade elaborando a prática mesma do governo; e, de outro lado, no último ano, o liberalismo contemporâneo americano e alemão entendido não como teoria econômica e como doutrina política, mas entendido como uma certa maneira de governar, como uma certa arte racional de governar. (FOUCAULT, 2014, p. 13. Nossos grifos).
} 
Na tese de Foucault o processo de enquadramento racional do poder que responde pela composição biopolítica do Estado moderno ("governamentalização"), parte, como tantas outras artes de governar, de uma apropriação transformadora das antigas práticas do poder pastoral de matriz cristã. Com efeito, em Segurança, território, população Foucault assume ao final da quarta aula que "essa governamentalidade nasceu, a partir de um modelo arcaico, da pastoral cristã" (FOUCAULT, 2008b, p. 146) cujo resultado, já no século XVII, é a instituição do mercantilismo como uma arte inteiramente nova de governo dos homens: um governo biopolítico na forma da economia. Os dispositivos de polícia e diplomático-militar emergem como os aparatos institucionais correlatos aos novos campos de intervenção, composição e gestão econômica das forças estatais que tem na população seu principal ativo.

A pastoral cristã é evocada por Foucault como prelúdio e a matriz genealógica de base das formas modernas da racionalidade biopolítica. O momento decisivo de tal hipótese reconstrói a origem pré-política do conceito de "governo" tal como ele emerge e se desenvolve na vasta literatura concernente ao problema da razão de Estado. Foucault registra que de maneira inteiramente inusitada com respeito à compreensão clássica da soberania jurídica e territorial e no confronto com a tradicional inscrição do político no contínuo teológico do governo de Deus sobre as almas e o mundo, o problema da razão de Estado, a partir do século XVI, articula-se em torno do projeto de conceber a especificidade da arte política de governo dos homens no contexto da esfera secular então emergente.

No pensamento político tradicional de filiação cristã, no modo como encontramos em Tomás de Aquino, por exemplo, os poderes do soberano sobre os súditos, do sacerdote sobre as almas e do pai sobre a família são derivações da autoridade originária e benfazeja que o DeusPastor exerce sobre seu povo-rebanho. Neste registro, o poder pastoral foi tradicionalmente compreendido como um continuum teológico que articula toda autoridade existente; desde a autoridade paterna à autoridade divina.

No limiar da modernidade o poder político começa a ser compreendido como acentuadamente distinto do poder espiritual exercido no filão da autoridade de Deus e segundo o novo referencial econômico trasladado da gestão familiar para a gestão pública; da administração das demandas e dos recursos domésticos para o incremento e a administração das forças do Estado. Em sua forma secularizada a arte política de governo dos homens foi concebida no ponto de encontro entre o nascimento da economia em sentido moderno de economia política (deslocada do modelo familiar para o público) e a gestão das populações e seus recursos vitais. Longe de elidir a influência do poder pastoral de matriz cristã, as injunções do processo de secularização levaram ao rearranjo do seu legado em função das atribuições gestoras do Estado que, a partir daí, transitam da boa condução das almas para a gestão benfazeja das vidas.

No contexto político, o problema de como conduzir condutas dos homens, mediado pelo afã de superação do governo exercido no plano espiritual em vista da salvação, engendra a indagação inaugural da razão de Estado. Foucault registra que a transposição da arte de governo do domínio espiritual ao secular ocorre no instante em que se assiste, no século XVI, a uma multiplicação, a uma difusão generalizada do problema de como conduzir-se no âmbito da vida privada (com reverberações na moral, na pedagogia e na medicina etc.) ou de como ser bem conduzido na vida pública; justamente o problema que concerne às inquirições em torno razão de Estado e que compõe o caráter propositivo da literatura anti-Maquiavel.

Foucault sustenta que "não houve, portanto", no limiar da modernidade, "passagem do pastorado a outras formas de conduta, de condução, de direção. Houve na verdade intensificação, multiplicação, proliferação geral da questão e dessas técnicas da conduta. Com o século XVI entramos na era das condutas, na era das direções, na era dos governos" 
(FOUCAULT, 2008b, p. 309). Assim, para além dos limites espirituais estritos do pastorado, o problema da condução de si e da condução dos outros pulula a partir do século XVI, atingindo notória expressão no campo político na condição de princípio aglutinador das mais variadas investigações em torno da racionalidade própria do poder político; o problema da razão de Estado.

Na mesma linha do governo espiritual ou à luz da forma como se exerce o poder no âmbito cristão, mas também no intuito de demarcar seu campo próprio de competência, a arte política de governo da conduta é elaborada em função do problema de como conduzir adequadamente e levar a bom termo a conduta dos outros no âmbito secular.

Dado que existe um princípio diretor, uma "razão" espiritual que legitima o princípio da obediência e organiza a tecnologia do governo das almas, aos que procuraram desloca-la do referencial escatológico importa indagar: qual a racionalidade própria do governo político dos homens? Quais objetivos e procedimentos tornam legitima a exigência política de obediência ao poder soberano secular? Qual é a arte específica do governo político dos homens quando é preciso desvencilhá-la, desanexá-la dos modelos tradicionais e da linha transcendente de legitimação do governo de Deus sobre as almas, do pastor sobre o rebanho, do pai sobre os filhos?

Eis o problema inaugural do processo de governamentalização do Estado, da racionalização da "arte de governar" os homens agora encarados como "população" e elemento decisivo das forças Estatais, partindo da gênese espiritual na direção a um enquadramento epistêmico crescente. Não no nascimento e nem tampouco no berço, foi no leito mesmo de sua concepção que o Estado moderno foi indexado ao exercício do governo sobre populações como expressão de uma à arte, dos saberes e das técnicas próprias à condução das condutas na esfera secular.

A hipótese de que o poder de "governo" sobre os homens é originariamente judaicocristão, assume que a atividade de "governar", em franca oposição ao modo como tem sido tradicional e confusamente compreendida, "não seja a mesma coisa que 'reinar', não seja a mesma coisa que "comandar' ou 'fazer a lei [...], não seja a mesma coisa que ser soberano"" (FOUCAULT, 2008b, p. 155). A forma política do poder de governo, cuja emergência é coeva ao Estado moderno, distingue-se da clássica forma jurídica da soberania (que justifica a obediência à lei em vista do bem comum) substituindo-a por estratégias e providências relativas à gestão e à boa condução dos homens e das coisas, nos termos das quais se redefinem suas atribuições. Daí que "os instrumentos de governo, em vez de leis, vão ser diversas táticas." (FOUCAULT, 2008b, p. 132).

Para Foucault, portanto, antes de se traduzir em competência política ou tecnologia geral de poder do Estado moderno, que é a forma histórica com que se consagrou, o exercício do governo sobre os homens foi primeiramente uma prerrogativa espiritual, uma tecnologia de pastoreio com a legitimidade ancorada na sabedoria e nas técnicas necessárias à boa condução das almas na direção seu destino escatológico.

Em suma, o pastorado [...] é uma arte de governar os homens, e é por aí, creio, que devemos procurar a origem, o ponto de formação, de cristalização, o ponto embrionário dessa governamentalidade cuja entrada na política assinala, em fins do século XVI, séculos XVII-XVIII, o limiar do Estado moderno. O Estado moderno nasce, a meu ver, quando a governamentalidade se torna efetivamente uma prática política calculada e refletida. A pastoral cristã parece-me ser o pano de fundo desse processo, estando entendido que há, por um lado, uma imensa distância entre o tema hebraico do pastor e a pastoral cristã e [que] haverá, é claro, outra distância não menos importante, não menos ampla, entre o governo, a direção pastoral dos indivíduos e das comunidades e o desenvolvimento das artes de governar, a especificação de um campo de intervenção política a partir dos séculos XVI-XVII. (FOUCAULT, 2008b, p. 219) 
O esforço filosófico de uma genealogia que nos remete à origem cristã da arte de governo, não apenas não pretende reabilitar a busca por princípios causais em história como se coloca em franca militância contra este empenho. A tese de que o Estado moderno, nas formas das governamentalidades mercantilista e liberal, reinstitucionalizou o poder pastoral, não supõe algo como uma equiparação ou alinhamento das práticas e nem tampouco dos propósitos das formas cristã e moderna de "governamento" (como de resto fica subentendo pela esfera da secularidade em que o próprio Estado se coloca na aurora da modernidade).Aliás, como disse Edgar do Castro (2016, p. 331), ao contrário das almas "as novas formas do poder pastoral concernem, precisamente, ao governo dos corpos, à disciplina, e ao governo das populações, à biopolítica", como tecnologias propriamente modernas de subjetivação e governamento da conduta. A genealogia foucaultiana do poder busca recompor as referências e os lastros históricos mais remotos e dispersos da governamentalidade.

\section{Governo e "atos de verdade" no cristianismo primitivo}

Foucault se interessa pelo cristianismo não enquanto conjunto doutrinário, mas como tecnologia de governo das almas que opera como referência histórica e forma organizacional do poder residualmente refletida no modo como as relações se arranjaram e ainda são arranjadas no Ocidente até os dias autuais. Isso vale para a genealogia da governamentalidade estatal que estrutura o curso Segurança, território, população e sua analítica do poder pastoral de 1978, mas também para o curso Do governo dos vivos de 1980.

Michel Senellart faz nos notar que o título curso deste 1980 é equívoco para o que aí está em causa. Na verdade, a formulação "do governo dos vivos" indica o que na primavera de 1979 Foucault havia projetado desenvolver na linha de continuidade do exame da biopolítica. Do governo dos vivos era, portanto, o título com que o autor pretendia retomar o desenvolvimento de uma tese posta na sombra, quando ao final do curso de 1979, no curso Nascimento da biopolítica, Foucault constatou não ter explorado a proposta que o animava desde o princípio, a saber, "estudar o liberalismo como grande geral da biopolítica" (FOUCAULT, 2008a, p. 30).

Tendo se estendido demais sobre aquilo que, segundo seu parecer final deveria ser o limiar do trajeto (o exame das formas contemporâneas do liberalismo), o autor pensava em continuar com o projeto no curso subsequente. Mas o que vemos no curso de 1980 é uma análise da decisiva relação entre verdade e subjetividade no cristianismo primitivo; os estudos dos "atos de verdade" que configuraram a forma de subjetivação que resultaria emblemática para Ocidente, com reverberações na filosofia, na ciência e no Estado moderno.

As conferências de 1980 são integralmente consagradas à elaboração do conceito de governo da conduta no eixo da relação cristã com a manifestação pura ou não utilitária da verdade a propósito do indivíduo (os chamados expedientes confessionais da ordem da ação que aí são denominados de "autoaleturgia") na correlação com a salvação. No curso Do governo dos vivos, no contexto da tradição cristã, o autor submete ao rigoroso crivo do exame genealógico uma proposição de base articuladora de toda sua filosofia, a saber, o princípio de que "o poder em geral não pode ser exercido se a verdade não for manifesta." (FOUCAULT, 2014, p. 67).

A autoaleturgia cristã é para Foucault o resultado do sistema confessional de práticas (batismo, penitência canônica e exame da consciência) pelo qual o crente/indivíduo, no espírito do que diz a verdade do dogma, é chamado a manifestar "atos de verdade"; a mostrar essa verdade a propósito de si, a verdade do que ele próprio é na condição de ser falível e 
perpetuamente pecador ${ }^{2}$. De todo modo, tais procedimentos compõem o segundo momento do processo aletúrgico que deve aduzir e completar no plano humano/mundano da subjetividade a dimensão primordial do sistema de verdade situado do lado do dogma, da fé ou da aleturgia divina. Esta que é a dimensão originária (a revelação divina da verdade): a condição transcendente e transcendental à manifestação da verdade subjetiva, correlata à "aleturgia judiciária" que procede por meio de técnicas de extração da verdade do/no indivíduo criminoso.

Num momento clarificador do curso que prepara a análise genealógica da relação entre verdade e governo da conduta no cristianismo primitivo, o processo aletúrgico assim compreendido, isto é, como estando encadeado por dois momentos complementares (as aleturgias subjetiva e divina), é metodologicamente abstraída por Foucault a partir de uma "leitura aletúrgica" da peça Édipo rei de Sófocles.

Depois de na primeira aula indicar que o objeto do curso de 1980 é a relação entre governo da conduta e aleturgia, o exercício do poder pela manifestação pura ou não utilitária da verdade, Foucault se dedicou nas duas aulas subsequentes a encontrar em Édipo rei um exemplo, um gabarito de inteligibilidade do processo aletúrgico no modo como acontece nos principais "atos de verdade" do cristianismo primitivo. O caso Édipo permite-nos entender que a "mecânica das metades" no processo aletúrgico envolve, em síntese, duas formas de distintas, não obstante integradas, de aleturgia: (a) a aleturgia divina ou a manifestação da verdade no plano transcendente e (b) a aleturgia das testemunhas ou a manifestação da verdade de tipo judiciária, com técnicas de interrogação, de exteriorização e de manifestação da verdade da alma, do eu ou dos indivíduos à luz da verdade originária sedimentada no dogma.

O problema em torno do eu implicado na "aleturgia das testemunhas" ou na "aleturgia judiciária", o procedimento de extração da verdade operado por Édipo sobre os escravos a partir de rituais e técnicas de interrogatório, elabora o esquema geral para compreensão das práticas de governo pela verdade no cristianismo primitivo. Daí que Do governo dos vivos, a despeito do título, se concentre no estudo dos ritos e procedimentos de "veridição"; nos procedimentos de verdade da aleturgia que incidem sobre a eu. Daí que as conferências se concentrem na tecnologia, no conjunto procedimental destinado a extrair a verdade da alma ou do sujeito sobre o qual o deus ou o dogma se pronuncia ${ }^{3}$.

Foucault insiste que o curso de 1980, na articulação com sua obra em geral, constitui parte de uma história da verdade que se desenvolve não sob perspectiva da objetividade, mas sob a perspectiva da objetivação de subjetividades, a saber, da configuração de sujeitos por referência à "verdade". Essa peculiar história da verdade do ponto de vista da subjetividade (que no fundo indaga pelo poder), se desenvolve na consideração da indexação do sujeito à verdade, aos "atos de verdade" da relação do sujeito consigo mesmo. Do que resulta a constituição de individualidades marcadas, formadas e subjetivadas segundo os modos múltiplos de relação com a verdade, a saber, os sistemas múltiplos de "veridição": cristianismo, filosofia moderna, ciência moderna, governamentalidade política etc.

\footnotetext{
${ }^{2}$ Mais precisamente, ao curso em questão importa a investigar o seguinte problema: "por que e como o exercício do poder em nossa sociedade, o exercício do poder como governo dos homens requer não apenas atos de obediência e de submissão, mas também atos de verdade em que os indivíduos, que são sujeitos na relação de poder, sejam também sujeitos como atores, espectadores testemunhas ou como objetos do procedimento de manifestação da verdade? Por que, nessa grade da economia das relações de poder, se desenvolveu um regime de verdade indexado à subjetividade [atos de confissão da verdade fundamental manifesta no sujeito, atos de autoaleturgia]? Por que o poder (e isso há milênios, em nossas sociedades) pede para os indivíduos dizerem não apenas 'eis-me aqui, eis-me aqui, eu que obedeço', mas lhes pede, além disso, para dizerem 'eis o que sou, eu que obedeço, eis o que sou, eis o que vi, eis o que fiz". (FOUCAULT, 2014, p. 76)

3 "Creio que temos aí um elemento importante, em todo caso é ele (e se insisti sobre isso da última vez foi por uma razão de método ou, digamos, de encaminhamento) que eu gostaria de procurar estudar um pouco este ano, quer dizer, o elemento da primeira pessoa, o elemento do 'eu', o elemento do 'authós', do 'eu mesmo' no que poderíamos chamar de aleturgia ou veridicção ou ritos e procedimentos de veridicção." (FOUCAULT, 2014, p. 46)
} 
[...] para uma história da verdade, uma história da verdade que não seria feita do ponto de vista das relações de objetividade, ou das estruturas de objetividade, ou da estrutura de intencionalidade. Tratar-se-ia de esboçar uma história da verdade que tomaria como ponto de vista os atos de subjetividade, ou ainda, as relações do sujeito consigo mesmo, entendidas não só como relação de conhecimento de si, mas também como exercício de si sobre si, elaboração de si por si, transformação de si por si, isto é, as relações entre a verdade e o que se chama de espiritualidade. (FOUCAULT, 2014, p. 105).

O projeto filosófico de uma história da verdade do ponto de vista da subjetividade ou o inventário e a análise dos "sistemas de veridição" e dos "atos de verdade" indexados ao sujeito, constitutivos da complexa e emaranhada rede de assujeitamento ocidental, é retrospectivamente evocado por Foucault como fio condutor de seu pensamento do ponto de vista privilegiado da subjetivação cristã. $O$ aspecto privilegiado da análise cristã que permite a Foucault perspectivar seu pensamento num novo eixo, deve-se ao fato de que também aqui estamos confrontados com um modo de subjetivação identificado como a matriz genealógica ocidental do governo pela verdade. É que a relação cristã entre verdade e governo da conduta (como na relação cristã entre governo e obediência) também prefigura, sob aspectos em nada negligenciáveis, diversas expressões modernas do poder, notadamente no que concerne à esfera política.

No mundo ocidental o cristianismo é a mais vigorosa e emblemática relação entre governo da conduta e verdade em sua forma pura, não utilitária, não econômica ou simplesmente "aletúrgica" - para ficarmos com a inventividade conceitual de Michel Foucault. Segundo os dados desta genealogia da relação entre poder e verdade, o aletúrgico cristão (conceito mesmo de uma relação específica entre verdade e governo) repercute de forma longeva e multifacetada até na vinculação da moderna produção da verdade ao exercício político poder e mesmo ao que nessa relação escapa à economia do que é meramente útil ao governar. É justamente nesta segunda dimensão da relação moderna entre verdade e poder, distinta e indissociavelmente imbicada na economia da verdade em função do governamento, que o aletúrgico permanece de algum modo inescapável mesmo às mais recentes tecnologias de poder enquanto opera como uma espécie de ponto último de ancoragem do governo pela verdade.

Observa-se que à contraluz da expressão do aletúrgico, isto é, da manifestação pura da verdade como efeito do poder, a relação entre governo e produção da verdade dirigida ao conhecimento útil ao governar (na forma como é flagrante nas práticas políticas de governo dos corpos e das populações) contém apenas elos utilitários ou econômicos com o saber, mas ainda sim indispensáveis à fundação do poder no marco da verdade. De fato, a despeito de aí a utilidade ao governamento operar como critério regulador do trato com a verdade, mesmo esta relação instrumental é igualmente requerida na delimitação do campo de competência, na elaboração das técnicas, no exercício e na legitimação do poder político do governo sobre os governáveis.

Rigorosamente falando, o exame da subjetivação cristã pela mediação da verdade impõe a Foucault a distinção analítica entre a manifestação pura ou não utilitária da verdade - que preside a relação entre sujeito e verdade no âmbito da aleturgia - e a produção do conhecimento útil ao governamento; própria das esferas nas quais o exercício do governo (como o atesta o domínio político e as várias instâncias modernas do poder) não seria possível sem conhecer as coisas, os homens e o meio de os governar.

Contudo, a crermos na análise foucaultiana, o vínculo moderno entre verdade e poder, para além da produção do conhecimento meramente útil ao governar, tangencia e retém ainda algo de residual e crucial da relação com o aletúrgico. Não é outra a razão da afirmação de que, mesmo nas condições modernas e contemporâneas, caracterizadas pela consolidação política da esfera secular, "se teria muita dificuldade para encontrar o exemplo de um poder que não se 
exerceria sem se fazer acompanhar, de uma maneira ou de outra, por uma manifestação [pura] de verdade." (FOUCAUTL, 2014, p. 6).

A análise genealógica da subjetivação cristã indica, portanto, como diz Foucault, "que não é simplesmente a necessidade [...] econômica, de conhecer o que se governa e como governar, não é simplesmente essa necessidade utilitária que pode permitir que se meça esse fenômeno que eu procurava indicar, a saber, a relação entre o exercício do poder e a manifestação da verdade." (FOUCAULT, 2014, p. 6). Seja no âmbito aletúrgico do puro desvelamento cujo ciclo engloba o sujeito-crente ${ }^{4}$, seja no plano do conhecimento econômico produzido na correlação direta com as demandas mais imediatas da arte de governar as populações, a verdade é aquilo que é sempre em algum nível mais puramente manifestada a respeito das coisas, dos homens ou dos meios de os governar.

Ora, é no que sustenta ser o limite da intersecção entre a manifestação pura da verdade e sua produção imediatamente voltada para o exercício do governo, portanto, no ponto de cruzamento entre a forma cristã primitiva e seus remanejamentos modernos no qual aletúrgico restaria contido, que Foucault concebe o próprio conceito de aleturgia.

Eu não diria mais simplesmente que o exercício do poder supõe naquele que o exerce qualquer coisa como um conhecimento, um conhecimento útil e utilizável para exercer o poder. Eu diria que o exercício do poder se acompanha bem constantemente de uma manifestação de verdade entendida no sentido amplo. E tentando encontrar uma palavra que corresponda não, portanto, ao conhecimento útil para esse que governa, mas para essa manifestação da verdade correlativa ao exercício do poder; enfim, procurando uma palavra eu encontrei uma que é bem velha porque é grega. [...] E por consequência, forjada a partir de alêthourguês [o verídico] uma palavra fictícia de alêthourgia, aleturgia, poder-se-ia chamar a manifestação da verdade como, portanto, um conjunto de procedimentos possíveis, verbais ou não, pelos quais se atualiza isso que é colocado como verdadeiro por oposição ao falso, ao oculto, ao invisível, ao imprevisível etc. Poder-se-ia chamar aleturgia esse conjunto de procedimentos e dizer que não existe exercício de poder sem qualquer coisa como uma aleturgia. Ou ainda, [...] porque o exercício do poder chama-se em grego hegemonia, não no sentido que damos hoje a essa palavra, mas hegemonia é simplesmente o fato de se encontrar, face aos outros, na possibilidade de conduzi-los e de conduzir, de algum modo, suas condutas; então eu diria que é bem provável que não exista nenhuma hegemonia que possa se exercer sem qualquer coisa como uma aleturgia (FOUCAULT, 2014, p. 8)

Mesmo a forma econômica da relação com a verdade, no domínio da qual o saber é interno à arte de governar, não pode prescindir de qualquer coisa de manifestação pura da verdade, de qualquer coisa de aletúrgico. O exercício do poder implica "como que um suplemento em relação a essa economia da utilidade" (FOUCAULT, 2014, p. 23). O aletúrgico, vínculo historicamente mais profundo da relação entre verdade e poder, em qualquer nível, está subjacente e é requerido mesmo nas distintas formas utilitárias de poder que marcam tão profundamente governo político dos homens na era modera.

Daí que mais do que um saber governar, um saber conduzir que sujeita a relação com a verdade aos termos mesmos da boa condução e das finalidades práticas que as preside, as governamentalidades do Estado mercantilista e do Estado liberal primeiro reivindicam ser, de um lado, a manifestação da verdade a propósito do que é o Estado, e de outro lado, a

\footnotetext{
${ }^{4}$ No que toca a aleturgia como forma cristã estrita da relação entre verdade e governo da conduta, Foucault se serve da expressão manifestação pura para caracterizar o exercício do poder fundado num tipo verdade que por ser da ordem da revelação, do dogma, por ser uma verdade não produzida, não utilitária ou não econômica, é por isso mesmo fundamental. Uma verdade que embora extravase amplamente o que é útil ao governamento, paradoxalmente lhe serve de suporte justamente enquanto, por oposição ao desconhecimento, tende ao desvelar-se e para tanto supõe o sujeito a quem ela concerne, sobre quem ela se pronuncia, sobre quem ele revela a verdade e de quem depende para sua manifestação no plano humano/mundano; esfera derradeira de seu acabamento, de sua completude.
} 
manifestação da verdade a respeito do que é a sociedade civil e a dinâmica de seus processos internos. No primeiro caso, a manifestação discursiva da verdade objetiva acera do Estado articula-se à racionalização institucional, à produção do saber-poder e às intervenções que dispõem o exercício do governo a convergir com o próprio saber objetivo acerca do Estado ${ }^{5}$.O mesmo se passa no segundo caso quando a manifestação da verdade objetiva acerca da sociedade como o lugar de processos espontâneos é que baliza a governamentalização do poder Estatal. Também aí a tecnologia política do poder de governo é concebida no horizonte do reencontro com a objetividade de que parte ${ }^{6}$.

A esse movimento circular da verdade objetiva ("aletúrgica") que tende a ser reencontrada ou manifesta no curso das disposições para as ações governamentais que ela organiza, Foucault não hesita em qualificar como sintomático da "estreiteza" das modernas maneiras de pensar as relações entre manifestação da verdade e exercício do poder.

Estreiteza que poderíamos assinalar salientando o seguinte. Nessas maneiras modernas [...] de refletir as relações governo-verdade, por um lado, todas elas definem essas relações em função de um certo real que seria o Estado ou que seria a sociedade. A sociedade que seria o objeto de saber, a sociedade é que seria lugar de processos espontâneos [...]. E, por outro lado, outra limitação dessas análises: é que, vocês estão vendo, elas são feitas em função de um saber que teria sempre a forma do conhecimento mais ou menos objetivo dos fenômenos. (FOUCAULT, 2014, p. 17)

Em todo caso, longe de se dissipar ou mesmo de permanecer historicamente restrito aos limites do cristianismo primitivo, o aletúrgico da relação governo-verdade é redimensionado na forma de saber objetivo no contexto das governamentalidades modernas. Nelas os conhecimentos úteis ao governamento são a um só tempo manifestações e remissivas ao plano excedentário ou objetivo da verdade na relação com o governo da conduta. É na remissiva à dimensão aletúrgica (ou ao menos ao que dela resta na modernidade) que as práticas de governo encontram algum tipo de ancoragem última. $O$ governo pela mediação econômica do verdadeiro, próprio dos deslocamentos modernos, comporta seu próprio nível de exigência quanto à manifestação pura da verdade.

Para Foucault, é ao cristianismo que devemos retornar se quisermos considerar a forma crucial e mais profunda da relação entre governo -verdade segundo a qual "não se pode dirigir os homens sem fazer operações na ordem do verdadeiro, operações sempre excedentárias em relação ao que é útil e necessário para governar de uma maneira eficaz. (FOUCAULT, 2014, p. $17)$.

Neste registro alargado, aleturgia designa, portanto, o conjunto de procedimentos possíveis pelos quais se revela de alguma forma (pura ou composta, no cristianismo primitivo ou nas diferentes formas da governamentalidade moderna) aquilo que é tido como verdadeiro. Na hipótese de Foucault, a despeito da aleturgia ser uma forma arcaica de exercício do poder mediada pela manifestação pura verdade que quase desapareceu com o advento de uma arte racional de governar, ela tem extraordinário valor heurístico que pode operar como princípio de inteligibilidade das modernas governamentalidades enquanto estas possuem algo de marginal e residual da forma aletúrgica.

\footnotetext{
${ }^{5}$ “[...] Em suma, seria a ideia de que a racionalidade da ação governamental é a razão de Estado e que a verdade que é preciso manifestar é a verdade do Estado como objeto da ação governamental." (FOUCAULT, 2014, p. 14)

${ }^{6 "}[\ldots]$ É a ideia de que, se efetivamente o governo governa não de acordo com a sabedoria geral, mas com a verdade, isto é, de acordo com o conhecimento exata dos processos que caracteriza essa realidade que é o Estado - essa realidade que constitui uma população, uma produção de riquezas, um trabalho, um comércio -, se ele governa de acordo com a verdade, menos terá a governar. Quanto mais indexar sua ação à verdade, menos terá a governar, no sentido de que terá de tomar menos decisões que se imporão de cima para baixo, em função de cálculos mais ou menos incertos, a pessoas que as aceitarão mais ou menos bem." (Id., ibid.)
} 
"Nesse domínio como em outros", afirma o autor no tocante às investigações acerca do aletúrgico como eixo histórico da relação governo-verdade, "o que é marginal e o que é residual sempre tem, quando examinado de perto, seu valor heurístico, e o demais ou o pouco demais muitas vezes é, nessa ordem de coisas, um princípio de inteligibilidade." (FOUCAULT, 2014, p. 9)

Em síntese, nas práticas cristãs de subjetivação que repercutem na organização moderna do governo da conduta existem duas tecnologias que se concatenam e se perfazem: a dos atos de obediência; que compõem o modelo da pastoral, e a dos atos de verdade, concernentes ao "regime de verdade" e subjetivação pela aleturgia. Até aqui assinalamos, portanto, a distinção, a imbricação e a complementaridade das formas cristãs de assujeitamento por obediência (poder pastoral) e atos de verdade (governo pela verdade).

\section{Do governo da cidade ao governo dos homens}

A genealogia do Estado governamentalizado, tal como a lemos no curso Segurança, território, população, sustenta a tese de que três matrizes de poder se fundem na arte racionalizada de governo político dos homens, sendo a antiga pastoral cristã seu elemento embrionário e os dispositivos diplomático-militar e de polícia os instrumentos modernos que simultaneamente redirecionam e redimensionam o exercício do poder de condução ou de governamento dos homens. $\mathrm{E}$ isso especialmente porque põem em funcionamento um inusitado e crescente aparelhamento técnico-epistêmico da arte de governar que Foucault define como governamentalidade biopolítica.

Em suma, para Foucault, a racionalização das práticas de governo dos homens no Ocidente moderno, a governamentalidade biopolítica, (i) remonta à antiga elaboração do poder pastoral hebreu, (ii) atinge sua prefiguração história mais decisiva no modelo cristão de pastorado - amplamente difundido na Idade Média -e (iii) assume a nova forma políticoinstitucional moderna - no horizonte da qual ainda nos movemos -em reação a uma série de movimentos de contra condutas pastorais então emergentes. Estes movimentos, longe de dissipar ou varrer as influências do poder pastoral sobre as estratégias seiscentistas de poder, deflagram seu processo de modernização/racionalização cuja expressão mais longeva ocorre justamente no domínio público e responde pelo Estado moderno e seus mais recentes desdobramentos com as artes políticas de governo dos homens na forma da economia (mercantilismo, liberalismo e neoliberalismo).

O inventário foucaultiano dos usos políticos e, sobretudo, pré-políticos da palavra "governar" até o século XVI, nos dá conta de que eles têm em comum a compreensão de que os homens é que são governáveis. Individual ou coletivamente os homens é que são o objeto do poder de governo:

\footnotetext{
Nunca se governa um Estado, nunca se governa um território, nunca se governa uma estrutura política. Quem é governando são sempre as pessoas, são os indivíduos ou as coletividades. Quando se fala da cidade que se governa, que se governa com base nos tecidos, quer dizer que as pessoas tiram sua subsistência, seu alimento, seus recursos, sua riqueza, dos tecidos. Não é portanto a cidade como estrutura política, mas as pessoas, indivíduos ou coletividades. (FOUCAUTL, 2008b, p. 164).
}

Já a partir do século XVIo verbo governar, assim compreendido, começa a sagrar-se historicamente na unidade político-semântica em que o conhecemos hoje. A assunção do verbo "governar" como conceito de base do vocabulário político moderno é um fenômeno histórico inversamente proporcional à extenuação da polissemia que caracteriza seus usos privados nos contextos pedagógico, moral e médico. 
O autor explica que os usos não negligenciáveis da palavra "governo" na literatura política grega, com testemunhos exemplares na peça Édipo rei de Sófocles e no diálogo Político de Platão, são concernentes a um registro semântico completamente distinto da compreensão moderna de que os homens é que são governáveis. Na literatura antiga a metáfora ou a imagem mais recorrentemente explorada como princípio de inteligibilidade do poder de governo, enquanto arte política, é a metáfora do timoneiro e do navio. Aí o governar é situado fundamentalmente na relação de direção que o timoneiro confere à embarcação confiada à sua arte de conduzir, de sorte que o bem governar se define com a adequada condução do barco ao porto. Desse modo, governar é antes de tudo evitar os escolhos, antecipar-se aos piratas, encontrar bons pontos de ancoragem e bem conduzir o barco ao seu destino mesmo em meio a intempéries.

Foucault insiste que por essa imagem a antiga arte política do governo deve ser compreendida como aquilo que se dirige fundamentalmente à cidade e apenas tangencialmente aos homens. Como o capitão do barco não governa os marujos, mas antes o navio em que se encontram, o governo político no mundo antigo não é concebido e nem tampouco elaborado em referência direta aos homens sobre os quais não se tem o poder de governo. No contexto antigo a arte política de governo é elaborada por alusão à cidade na qual os homens estão circunscritos. $O$ saber governar é um saber que concerne à cidade. Daí que os homens estejam incidental e não imediatamente implicados na arte e no poder de governo. Enfim, "a cidade em sua realidade substancial, em sua unidade, com sua sobrevivência possível ou seu desaparecimento eventual, isso é que é o objeto do governo, o alvo do governo." (FOUCAULT, 2008b, p. 165). À diferença da modernidade na tradição greco-romana não é o homem, mas a cidade e o Estado que são governáveis.

A cidade, este quadro de referência do saber/poder do governo político, efetivamente figura como objeto de poder de forma exemplar na obra Édipo rei que Foucault examina em duas das doze aulas do curso Do governo dos vivos, particularmente quando aí analisa a especificidade da "arte edipiana" de governar. O objeto e a tarefa de do governo político são tipificados no quadro da metáfora do governo do timoneiro sobre embarcação.

O que significa o qualificativo Rei conferido Édipo no título da célebre peça de Sófocles? Qual é a especificidade da arte edipiana que o habilita ao governo político? Édipo sabe e deve governar Tebas segundo suas necessidades porque é aquele cuja técnica de penar e descobrir por indícios lhe permite escapar mesmo aos decretos divinos a que Tebas possa estar sujeita. $O$ governo de Édipo é o governo de Tebas e não o governo dos tebanos. O poder de governo sobre a cidade, como Édipo o exerce, supõe o seu julgamento próprio, supostamente requerido em cada circunstância particular à boa condução da cidade. A razão com que Édipo foi legitimado como "tirano de Tebas" quando a salvou em um momento crucial, também lhe dá, no contexto grego, o direito de proteger e conduzir a cidade como um timoneiro a seu barco.

Em suma, a arte peculiar de Édipo, e aquela em cujo exercício público ele se firmará na condução/governo de Tebas, é a de pensar e "descobrir por indícios". Usando a célebre imagem marítima grega, trata-se de antecipar por indícios onde estão os recifes, os escolhos e as pedras à flor da água de cuja direção um bom condutor do barco, e o tirano relativamente à cidade, saberá bordejar e atingir com segurança seu desígnio que é cais. No limite, mesmo quando a arte política do tirano, compreendida como "arte do leme" se depara com os decretos divinos sobre a cidade, neles não vê mais do que outros escolhos dentre os quais é preciso encontrar o melhor caminho possível.

Do ponto de vista político, o pano de fundo da trágica "inconsciência" de Édipo não é tanto ou somente o fato de que encontrará a si próprio nos autos do inquérito que conduz em virtude de sua arte extraordinária. Quando Édipo se serve de sua técnica característica para pensar e encontrar por indícios o assassino que maculou Tebas com o sangue de Laio (seu rei 
pregresso), expondo assim a cidade à ira dos deuses que ele deseja aplacar, mais do que pessoal a tragédia é política: há uma desarmonia entre a arte edipiana que salvou e fundou seu governo sobre Tebas e o que é instituído pelos deuses. Os decretos divinos que o juraram no plano pessoal se mostram efetivamente incontornáveis na condição de homem público, de rei ou de governante de Tebas.

É claro, portanto, que o trágico acontece na região limítrofe entre o destino pessoal de Édipo e sua condição de Rei de Tebas, pois sobre Édipo recai desde o princípio o oráculo incontornável de matar o pai e casar-se com mãe; o mesmo que acarreta ainda o esforço de fuga no curso do qual ele atingirá a posição de rei. Em outras palavras, na leitura de Michel Foucault a manutenção do poder de governo sobre Tebas exige de Édipo a conciliação impraticável entre a qualidade pessoal ou a técnica que funda seu poder de governo sobre a polis e o modo originário como ele encara os decretos divinos, a saber, como escolhos contornáveis pela arte humana.

Qualquer que seja a Sorte de Édipo rei, o enredo da trama é evocado por Foucault como testemunho histórico exemplar do modo como os antigos compreenderam e praticaram a arte política de governo. A pertinência política do saber de Édipo é análoga à do timoneiro. A diferença é que arte de Édipo é a de governar a polis, enquanto que o piloto governa o navio. Em ambos os casos está em jogo governo das coisas e não homens. Para Foucault é no Oriente pré-cristão e depois no próprio Oriente cristão que se deve buscar a elaboração original da noção decisiva à governamentalidade biopolítica de que os homens são governáveis. 


\section{Referências}

CANDIOTTO, César. A governamentalidade política no pensamento de Foucault. Filosofia Unisinos, 11(1): 33-43, jan./abr. 2010.

CASTRO, Edgardo. Vocabulário Foucault. Um percurso pelos seus temas, conceitos e autores. $2^{\mathrm{a}}$ ed. Trad. Ingrid Müller Xavier. Ver. téc. Walter Omar Kohan \& Alfredo Veiga-Neto. Belo Horizonte, Rio de Janeiro, São Paulo: Grupo Autêntica, 2016.

FOUCAULT, Michel. Do governo dos vivos. Trad. Eduardo Brandão. São Paulo: Martins Fontes, 2014.

FOUCAULT, Michel. Em defesa da sociedade. Trad. Martina Ermantina Galvão. São Paulo: Martins Fontes, 2005.

FOUCAULT, Michel. História da sexualidade. Trad. Pedro Tamen. Lisboa: Relógio D’Água Editores, 1994.

FOUCAULT, Michel. Microfísica do poder. Trad. Roberto Machado. Rio de janeiro: Edições Graal, 2011.

FOUCAULT, Michel. Nascimento da biopolítica. Trad. Eduardo Brandão. São Paulo, 2008a.

FOUCAULT, Michel. Segurança, território, população. A vontade de saber. Trad. Eduardo Brandão. São Paulo: Martins Fontes, 2008b.

FOUCAULT, Michel. Vigiar e punir. 32 ed. Rio de Janeiro: Editora Vozes, 1997.

REVEL, Judith. Dicionário Foucault. Trad. Anderson Alexandres da Silva. Rio de Janeiro: Forense Universitária, 2011.

Autor(a) para correspondência: Cícero Josinaldo da Silva Oliveira, Praça Brasil Gomes Caiado, nº 35, Centro, 76600-000, Cidade de Goiás - GO, Brasil. cicerojosinaldo@ufg.br 